\title{
Evaluation of In-Process Laser Heat Treatment on the Stress Conditions in Laser Metal Deposited Stellite ${ }^{\circledR} 21$
}

\author{
Grant L. Payne ${ }^{1, a}$, Ioannis Violatos ${ }^{1, b}$, Stephen Fitzpatrick ${ }^{1, c, *}$, \\ David Easton ${ }^{1, \mathrm{~d}}$ and Joshua Walker ${ }^{1, \mathrm{e},{ }^{\star}}$ \\ ${ }^{1}$ Advanced Forming Research Centre, 85 Inchinnan Drive, Glasgow, Scotland (UK), PA 9LJ \\ agrant.payne@strath.ac.uk, bioannis.violatos@strath.ac.uk, cs.fitzpatrick@strath.ac.uk, \\ ddavid.easton@strath.ac.uk, ${ }^{\mathrm{d}}$ joshua.walker@strath.ac.uk
}

Keywords: Additive Manufacturing, Laser Metal Deposition, Residual Stress, XRD, Contour Method, Micro-Hardness, Energy Density, Micro-Structural Analysis

\begin{abstract}
Laser Metal Deposition with Powder (LMD-p) has been investigated as a means of Remanufacturing high value components, such as tooling, dies and moulds. However, the LMD-p process is known to develop high levels of residual stresses within the builds, which may have an effect on the mechanical performance of the components. Heat treatment is a common method for stress relieving, however, large components or those undergoing ReManufacturing may not be suitable for conventional stress relieving heat treatments processes, such as those using a furnace. Therefore, localised and dynamic heat treatment using the laser installed on the LMD- $p$ apparatus has been investigated as means of providing stress relieving heat treatment. As such, research to understand the generation and distribution of stresses has been undertaken in conjunction with micro-structural analysis to provide a robust evaluation. A combination of Contour Method, XRD, Micro-Hardness and SEM imaging was used for analysis. Preliminary assessments have largely shown positive results as the specimen with in-process heat treatment has exhibited low and relatively uniform stress fields.
\end{abstract}

\section{Introduction}

ReManufacturing tools and dies is increasing in popularity owing to its time efficiency, waste reduction and cost savings with respect to machine/production down time [1-4]. LMD-p can selectively deposit material in regions of wear and/or fatigue to extend a product's life or increase its performance, however, a limitation of the process is thermal shock to the substrate and high residual stresses created within the builds. Traditional heat treatment processes such as annealing rely on placing the entire component within a furnace to undergo stress relieving heat treatment.

Industrial interest and government led policy have led to increased research activity in the field of additive manufacturing. In one such project, in a baseline study Stellite ${ }^{\circledR} 21$ was deposited on AISI H13 Steel with a standard set of parameters, this build strategy exhibited high stresses [5]. A similar project reported the high stresses in LMD-p Stellite ${ }^{\circledR} 21$ to have been reduced through conventional furnace based heat treatment [6].

\section{Experimental Method}

Cylindrical billets of AISI H13 Tool Steel (diameter 21mm x 26mm height) were cut from wrought blocks using EDM and turning, ensuring that the recast layer was removed before deposition. Custom LMD-p apparatus was used to deposit the Stellite ${ }^{\circledR} 21$ using a Trumpf TruDisk 2002 1030nm Laser at Laser Additive Solutions Ltd, Doncaster using the process parameters defined in Table 1. 
Localised heat treatment was achieved by defocusing the laser beam (increasing the Laser Stand Off distance), lowering the Laser Power and running successive, overlapping passes across the substrate's top surface. The material was preheated to $\sim 450^{\circ} \mathrm{C}$ and the temperature was monitored using a LAND ARC Thermal Camera before deposition began. This heating program was then repeated at $6.5 \mathrm{~mm}$ intervals, with a final heat treatment at build completion as detailed in figure 1.

Table 1. LMD-p Process Parameters

\begin{tabular}{cccccc}
\hline Laser Power & $\begin{array}{c}\text { Laser Stand } \\
\text { Off }\end{array}$ & Feed Rate & Spot Size & $\begin{array}{c}\text { Z Build } \\
\text { Height }\end{array}$ & $\begin{array}{c}\text { Energy Density } \\
\text { (Eq. 1) }\end{array}$ \\
\hline Deposition: $575 \mathrm{~W}$ & $12 \mathrm{~mm}$ & $8 \mathrm{~mm} / \mathrm{s}$ & $1.5 \mathrm{~mm}$ & $\begin{array}{c}0.3 \\
\text { mm }\end{array}$ & $47.92 \mathrm{~J} / \mathrm{mm}^{3}$ \\
Heat Treatment: $250 \mathrm{~W}$ & $112 \mathrm{~mm}$ & $10 \mathrm{~mm} / \mathrm{s}$ & $10 \mathrm{~mm}$ & mmer & $2.50 \mathrm{~J} / \mathrm{mm}^{3}$ \\
\hline
\end{tabular}

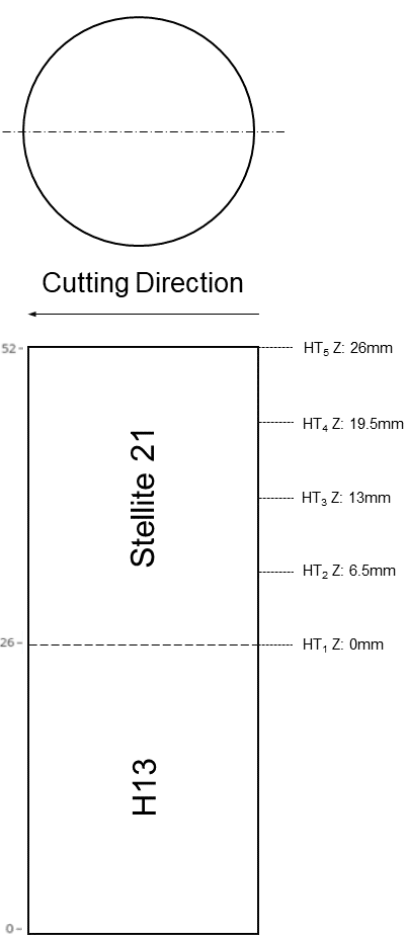

Figure 1. Specimen Schematics

Table 2. Chemical Composition of Stellite ${ }^{\circledR} 21$, Manufacturer Specification in wt.-\%

\begin{tabular}{cccccc}
\hline Co & Cr & Mo & C & Ni & $\begin{array}{c}\text { Other Elements } \\
\text { Present }\end{array}$ \\
\hline Base & $26-29$ & $4.5-6.0$ & $0.20-0.35$ & $2.0-3.0$ & Fe, Si, Mn \\
\hline
\end{tabular}

Table 3. Chemical Composition of AISI H13 Tool Steel, Manufacturer Specification in wt.-\%

\begin{tabular}{ccccccc}
\hline $\mathrm{Fe}$ & $\mathrm{C}$ & $\mathrm{Mn}$ & $\mathrm{Si}$ & $\mathrm{Cr}$ & $\mathrm{Mo}$ & $\mathrm{V}$ \\
\hline Base & 0.4 & 0.4 & 1.0 & 5.2 & 1.4 & 1.0 \\
\hline
\end{tabular}

Table 4. Mechanical Properties of AISI H13 Steel \& Stellite ${ }^{\circledR} 21$ [1]

\begin{tabular}{ccc} 
& Young’s Modulus [MPa] & Poisson`s Ratio \\
\hline AISI H13 & 210000 & 0.30 \\
\hline Stellite 21 & 215000 & 0.21 \\
\hline
\end{tabular}

$$
\text { Energy Density }\left(\frac{J}{\mathrm{~mm}^{3}}\right)=\frac{\text { Laser Power }(W)}{\text { Feed Rate }\left(\frac{m m}{\mathrm{~s}}\right) * \operatorname{Spot} \text { Size }\left(\mathrm{mm}^{2}\right)} \quad \text { Eq. } 1
$$

Zavala-Arrdendo developed an equation Eq. 1 in which it is apparent that energy density is a key process driver that is governed by three of the most imperative process parameters [7]. It determines to the amount of energy transferred to a given area (Spot Size) at any given moment.

Each parameter can be independently modified to reach a desired energy density, however, they must be carefully balanced in order to achieve suitable material properties and build speed. Increasing Laser Power to increase energy density will raise thermal gradients and affect cooling rates. If the Feed Rate and or Laser Spot Size are lowered to increase the energy density then the build time will significantly increase, the latter is due to the track width becoming narrower. If large amounts of energy are rapidly transferred to the substrate this will cause: thermal shock, distortion and high levels of oxidisation, therefore, energy must be transferred, incrementally, to avoid the aforementioned defects. 


\section{Micro-Structural Analysis}

The characterisation of the micro-structure was carried out on a FEI Quanta 250 FEG SEM at the AFRC. As previously described, the specimens were mechanically ground and polished, but not etched as the commonly used Kallings no. 2 etchant has been observed to adversely affect the H13. A suitable etching method to enhance micro-structure visibility has not yet been found for H13 / Stellite ${ }^{\circledR} 21$.
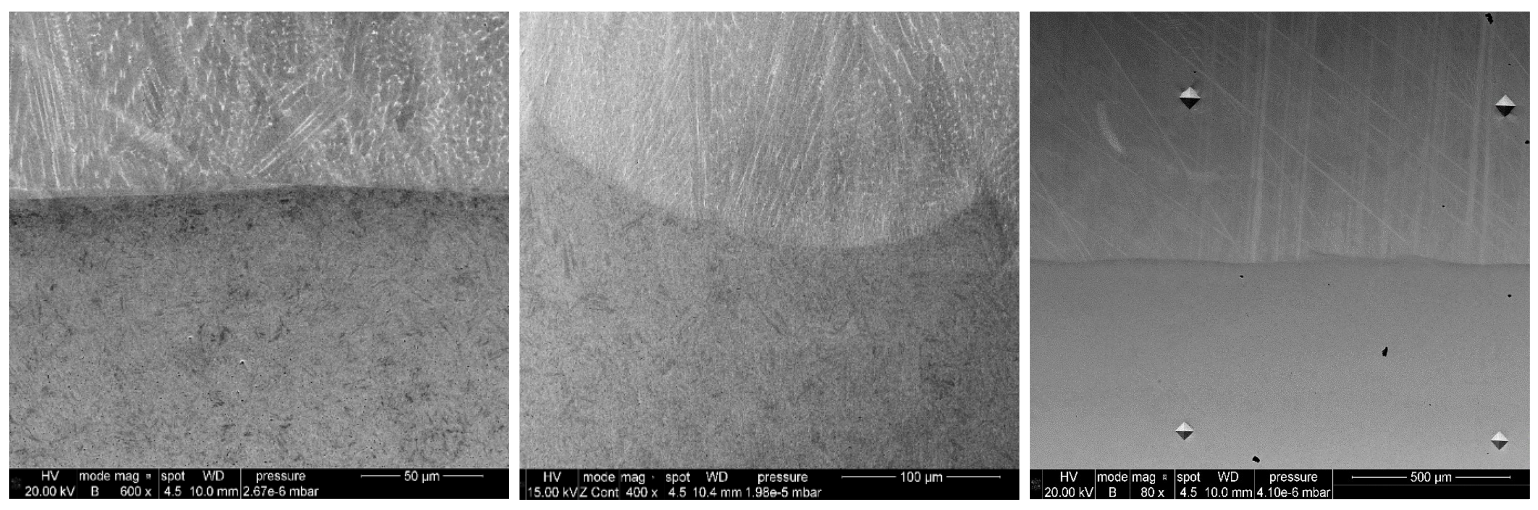

\section{Figure 2. (a) H13 / Stellite ${ }^{\circledR}$ Interface (b) Stellite Weld Bead (c) Interface Showing Hardness Indentations}

Micro-structural analysis revealed columnar grain growth perpendicular to the interface. Similar structures were observed at the build edges. Grain structure within the central bulk of the build was mostly equiaxed, this is most likely a product of slower cooling rates. No significant defects or cracking was observed at the heat-treatment z-levels. Small amounts of porosity (trapped carrier gas) and build defects were observed throughout the build, the magnitude of which did not raise concerns. The $\mathrm{H} 13$ revealed a HAZ ranging from $~ 500 \mu \mathrm{m}$ to $\sim 750 \mu \mathrm{m}$ shown as a lighter coloured region on the images. However, the thermally softened region was not visible by SEM analysis but was revealed in the Micro-Hardness examination (Figure 3).

\section{Micro-Hardness Analysis}

The specimen was analysed on a Zwick ZHV1 - Micro Vickers Hardness Tester using a 1mm x $1 \mathrm{~mm}$ matrix and HV1 indentations. Points were carefully aligned with the interface, with a row falling $~ 500 \mu \mathrm{m}$ either side of the interface as shown in Figure 2 (c).

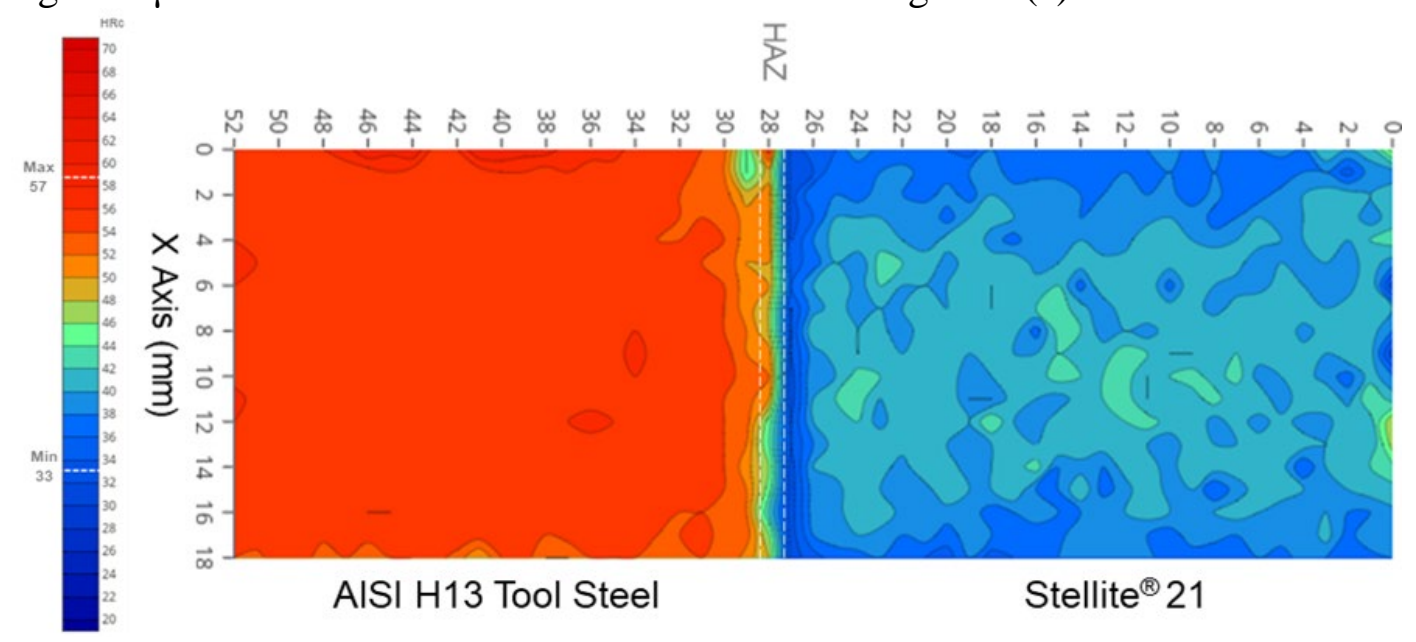

Figure 3. Micro-Hardness Contour Map

Measurements were converted as per ASTM E140 -12be1 [8] from Vickers to Rockwell and a contour map (Figure 3) was created using Plotly online software. The average value for H13 was 
54.0 $\mathrm{HR}_{\mathrm{C}}$, 39.76 $\mathrm{HR}_{\mathrm{C}}$ for Stellite 21 and $41.05 \mathrm{HR}_{\mathrm{C}}$ in the HAZ. A decline in hardness is observed in the H13 Steel at the interface, this extends beyond the HAZ ( 500 $\mu \mathrm{m}-750 \mu \mathrm{m})$ to $\sim 3 \mathrm{~mm}$ into the substrate. The change is fairly minor $54.0 \mathrm{HR}_{\mathrm{C}}-49.35 \mathrm{HR}_{\mathrm{C}}$ indicating that the preheating has had a limited effect on the H13.

\section{Residual Stress Measurement - Contour Method}

The Contour Method calculates the out of plane residual stress by precisely cutting a specimen into two pieces, measuring the resulting deformation and relaxation due to residual stress redistribution and lastly running a Finite Element simulation \{Prime, 2001 \#1;Prime, 2013 \#12 .

The component to be measured is sectioned along the plane of interest using EDM wire erosion. The two cut faces are then measured to determine the surface topology to which a surface contour can be analytically determined. This can be incorporated into a FE simulation to determine the pre-existing residual stresses prior to EDM sectioning. This makes Contour Method a useful tool for assessing complex residual stress fields such as those found in weld interfaces or ALM parts.

The specimen was clamped and cut longitudinally with a $0.25 \mathrm{~mm}$ wire across the diameter using EDM to create to equal halves, parallel and perpendicular to the LMD-p build as noted in Figure 1. Cut surfaces were measured using a CMM at the AFRC with a $0.2 \mathrm{~mm} \times 0.2 \mathrm{~mm}$ measurement matrix. A Mitutoyo Crystal Apex C CMM was used with a $1 \mathrm{~mm}$ diameter Ruby attached to a Renishaw ${ }^{\circledR}$ PH10T probe. The measured surface topography was prepared using MATLAB $^{\circledR}$ for a Finite Element simulation in Abaqus ${ }^{\mathrm{TM}}$. Using the outline from the CMM a geometry was recreated in Abaqus ${ }^{\mathrm{TM}}$ and partitioned into two regions with their respective elastic-mechanical properties Table 4.

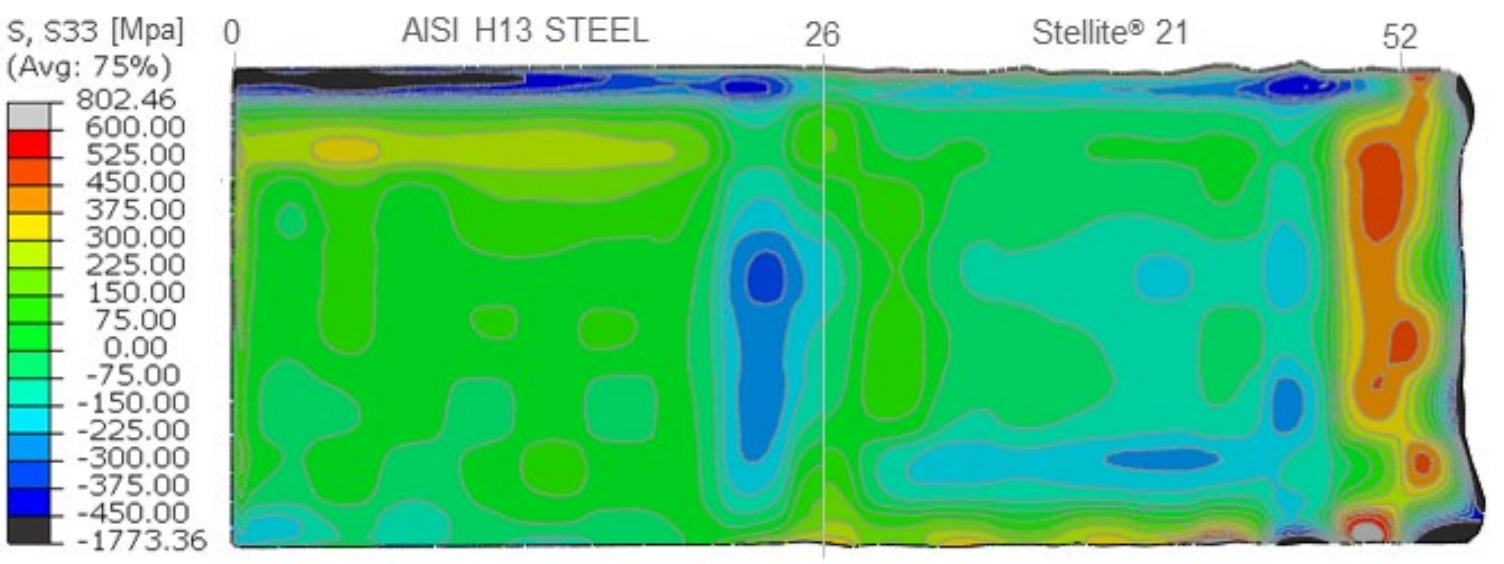

Figure 4. Contour Residual Stress Map

Figure 4 shows a compressive residual stress field originating at the interface and extending $3 \mathrm{~mm}$ into the H13 material. This correlates with the thermally softened region (Figure 3). A zone of tensile stress adjacent to the build finish in Stellite is displayed with an equilibrated compressive stress region. This is most likely attributed to the accelerated cooling rates experienced. In ReManufacturing some of this tensile zone would be machined away, however, this would not remove these stresses and it is crucial to note that work must be undertaken to analyse stress redistribution and relaxation in such conditions. The specimen exhibited comparatively lower stresses to the baseline process/operation [5]. EDM cutting artefacts introduced errors in the residual stress analysis (grey areas shown in Figure 4).

\section{Residual Stress Measurement - X-Ray Diffraction Method}

The specimen was examined using a PROTO LXRD diffractometer at the AFRC with using the parameters detailed in Table 5 and the best practice standards set out by the National Physics Laboratory [10]. Round apertures with diameters of $0.15 \mathrm{~mm}$ and $1 \mathrm{~mm}$ were used with 
measurements beginning at the H13/Stellite ${ }^{\circledR}$ interface in the centre of the build running from $(10.5,26)$ to $(10.5,21.25)$. Measurements were concentrated at the interface, to capture the transition and magnitude of the axial stresses in the HAZ. Points were then positioned at $0.5 \mathrm{~mm}$ intervals to capture bulk trends.

Table 5. XRD Parameters

\begin{tabular}{ccccccc}
\hline Material & Radiation Source & Tube Voltage & Tube Current & Wavelength & Bragg Angle & \{hkl Plane \\
\hline Ferrite BCC & Chromium Ka & $30 \mathrm{KV}$ & $25 \mathrm{~mA}$ & $2.291 \AA$ & $150.41^{\circ}$ & 211 \\
\hline
\end{tabular}

A Pre-Build H13 specimen without LMD-p was measured to provide guideline stress conditions for the substrate. Care was taken to mechanically polish both specimens in order to remove the recast layer caused by EDM sectioning - they were then electro-polished for 45 seconds to remove any mechanically induced stresses from polishing.

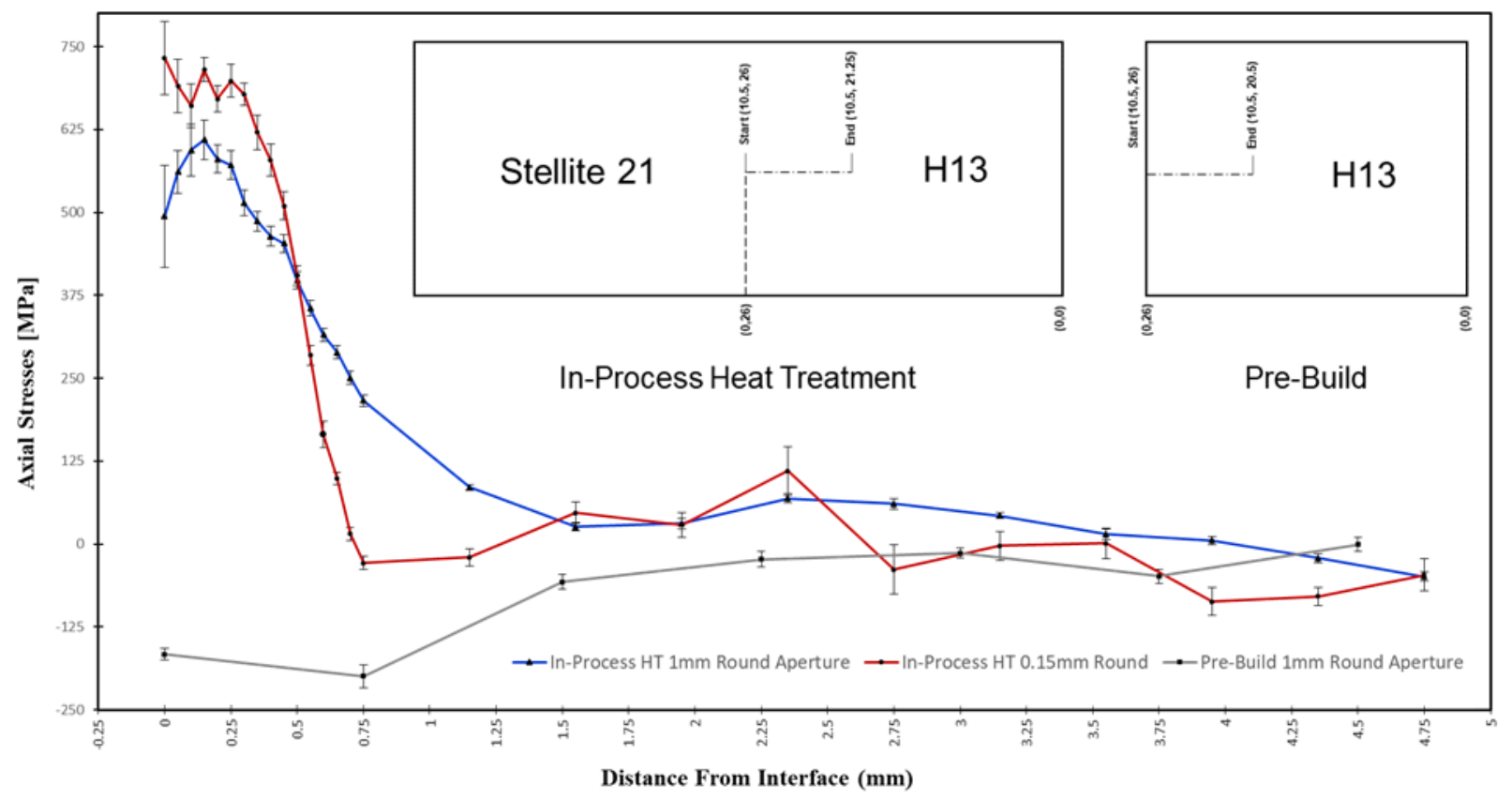

Figure 5. Axial Stresses in Relation to Distance from Interface and Measurement Location Schematic

Elasticity theory for isotropic solids and Hooke's law under plane stress conditions have been combined with the strains in terms of inter-planar spacing under different tilt angles $(\psi)$ obtained from Bragg's Law for diffraction, to produce the stress acting along a specific direction, Eq. 2.

$$
\sigma_{\varphi}=\frac{E}{(1+v) \sin ^{2} \psi}\left(\frac{d_{\psi}-d_{n}}{d_{n}}\right)
$$

where E is the Young's modulus, $v$ is the Poisson's ratio, ? $]_{0}$ inter-planar spacing of planes at a tilt angle $\psi$ to the surface and $?_{\square}$ is inter-planar spacing of planes normal to the surface [10].

In the HAZ, a trend from high tension ( 700MPa) to a low compression stress state is observed. Immediately following this $(25 \mu \mathrm{m}$ to $125 \mu \mathrm{m})$ in the $0.15 \mathrm{~mm}$ aperture series there is a dip to $50 \mathrm{MPa}$ of compressive stresses, this is most likely a localised equilibrium effect caused by the tensile stresses in the HAZ. This effect is not fully observed in the $1 \mathrm{~mm}$ aperture series due to an averaging effect in the diffraction area, this is a limitation of using a larger aperture. Therefore, future work could use this combination in order to observe localised trends and to validate global trends. 


\section{Summary}

Preliminary investigation broadly showed positive results as the specimen with in-process heat treatment has exhibited lower and more uniform residual stress fields with respect to the baseline LMD-p specimen [5]. However, thermal softening and axial stresses at the H13 interface appeared greater in the heat-treated specimen. This partially contradicts the results from the Contour Method data, thus warranting further examination of the residual stresses. Crystallographic analysis using EBSD and EDX could be undertaken to examine the possibility of micro-structural alterations influencing these readings. Further mechanical testing and finite element analysis will provide a more comprehensive understanding of the effect of in-process heat treatment on parts ReManufactured using LMD- $p$.

\section{Acknowledgments}

I would like to thank the EPSRC (EP/I015698/1), HVM Catapult and the AFRC for their financial assistance without which this research would not have been possible. The following people should be acknowledged for their technical assistance and expert advice: Liza Hall, Ryan O’Neil, Giribaskar Sivaswamy, Himanshu Lalvani, Shanmukha Moturu, Kornelia Kondziolka \& Abigail Ellison Plot.ly should be thanked for their software. The Materials \& Residual Stress team and Machining group at the AFRC should be acknowledged for their contribution in this research project.

\section{References}

[1] Toumi, M., et al. Residual Stress Analysis of Stellite-coated Forging Tool Steel Using Synchrotron Radiation Diffraction. in Materials Science Forum. 2012. Trans Tech Publ.

[2] Birol, Y., Thermal fatigue testing of Inconel 617 and Stellite 6 alloys as potential tooling materials for thixoforming of steels. Materials Science and Engineering: A, 2010. 527(7-8): p. 1938-1945. https://doi.org/10.1016/j.msea.2009.11.021

[3] Mudge, R.P. and N.R. Wald, Laser engineered net shaping advances additive manufacturing and repair. Welding Journal-New York-, 2007. 86(1): p. 44.

[4] Payne, G., et al., Remanufacturing H13 Steel Moulds and Dies Using Laser Metal deposition. Advances in Manufacturing Technology XXX; IOS Press: Amsterdam, The Netherlands, 2016: p. 93.

[5] Cullen, C., et al., AFRC CATP 764 Suitability of LMD for Oil and Gas Cladding and Die Remanufacture. 2018, University of Strathclyde: Advanced Forming Research Centre.

[6] Cullen, C., et al., AFRC CATP 463 Additive Die ReManufacturing. 2017, University of Strathclyde: Advanced Forming Research Centre.

[7] Zavala-Arredondo, M., et al., Laser diode area melting for high speed additive manufacturing of metallic components. Materials \& Design, 2017. 117: p. 305-315. https://doi.org/10.1016/j.matdes.2016.12.095

[8] Designation, A., Standard Hardness Conversion Tables for Metals Relationship Among Brinell Hardness. Vickers Hardness, Rockwell Hardness, Superficial Hardness, Knoop Hardness, Scleroscope Hardness, and Leeb Hardness, ASTM international E140-12b, 2013. 1.

[9] Prime, M.B., Cross-sectional mapping of residual stresses by measuring the surface contour after a cut. Journal of engineering materials and technology, 2001. 123(2): p. 162-168. https://doi.org/10.1115/1.1345526

[10]Fitzpatrick, M., et al., Determination of residual stresses by X-ray diffraction. 2005. 